\title{
CINZA DO BAGAÇO DE CANA-DE-AÇÚCAR COMO AGREGADO EM CONCRETOS E ARGAMASSAS
}

\section{Sugarcane bagasse ash as concrete and mortar aggregate}

\author{
Romel Dias Vanderlei ${ }^{1}$, Hugo Sefrian Peinado ${ }^{2}$, Marisa Fujiko Nagano ${ }^{3}$, \\ Rafael Germano Dal Molin Filho ${ }^{4}$
}

Recebido em 15 de julho de 2013; recebido para revisão em 11 de agosto de 2013; aceito em 03 de dezembro de 2013; disponivel on-line em 06 de março de 2014.

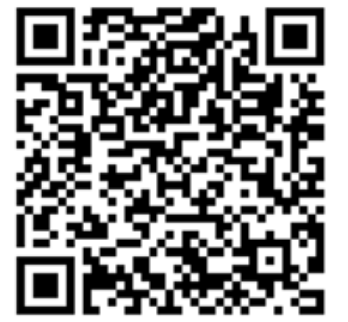

\section{PALAVRAS CHAVE:}

Cinza do bagaço da canade-açúcar;

Agregado miúdo;

Concretos;

Argamassa.

\section{Keywords:}

Sugarcane bagasse ash;

Fine aggregate;

Concrete;

Mortar.

\section{* Contato com o autor:}

${ }^{1}$ e-mail : rdvanderlei@uem.br

2e-mail : hspeinado@gmail.com

e-mail : nfmarisa@hotmail.com (M. F. Nagano) Mestranda, Programa de Pós-graduação em Engenharia Urbana, Universidade Estadual de Maringá, Maringá.

${ }^{4}$ e-mail : rafagermano@hotmail.com (R. G. Dal Molin Filho )

Prof. MSc., Departamento de Engenharia de Produção, Universidade Estadual de Maringá
RESUMO: Atualmente, há uma série de pesquisas em todo o mundo que se concentram na busca por formas de utilização de resíduos industriais ou agrícolas como fonte de matérias-primas para a indústria de construção. Na busca pela redução do consumo de recursos naturais, associado ao aquecimento observado no setor da construção civil, verifica-se o incentivo aos estudos que visem o desenvolvimento de agregados alternativos oriundos destes resíduos para utilização em concretos e argamassas, tal como a cinza do bagaço da cana-de-açúcar (CBC). Assim, o presente bagaço da cana-de-açúcar como agregado miúdo em concretos e argamassas. Para anto, procedeu-se a uma revisão bibliográfica e compilação de dados acerca do dados destacados no presente estudo, foi possível concluir que há viabilidade técnica e ambiental na utilização da $\mathrm{CBC}$ em concretos convencionais, auto densáveis e argamassas, garantindo um destino técnico com valor agregado ao extração de areia de leitos dos rios, evitando uma série de impactos negativos oriundos da atividade de extração. No entanto, enfatiza-se que estudos específicos para cada caso em que se deseja fazer a aplicação de CBC,

ABSTRACT: Several studies around the world have been focusing on the search for industrial or agricultural wastes as a source of raw matierials for the construction industry. In efforts to reduce consumption of natural resources associated with the growth observed in the construction industry, there is the incentive for studies aimed at the development of alternative aggregates from these residues for concrete and mortars, such sugarcane bagasse ash (SBA). Thus, this study intends to identify the state of the art of the application of the sugarcane bagasse ash as fine aggregate in concrete and mortar. Therefore, it was proceeded to a literature review and compilation data about the subject. From the data highlighted in this study, it is concluded that there was technical and environmental viability in using SBA in conventional concretes, mortars and self-compacting concrete, certifying a destination technical with value added to the residue from burning sugarcane bagasse and, consequently, decreasing the extraction of sand from riverbeds, avoiding a number of negative impacts resulting from the extraction activity. However, it is emphasized that specific studies should be executed for each situation that application of SBA is possible, mainly due to the characterisitics of the material. 


\section{INTRODUÇÃO}

A temática da sustentabilidade é apontada como uma iniciativa em produzir bens que gerem a menor carga ambiental possível, no intuito de preservar o ambiente de degradações futuras. Deste modo, para a obtenção do desenvolvimento sustentável, é indispensável fazer a dissociação entre o desenvolvimento tecnológico e a carga ambiental, ou seja, deve-se procurar obter o mesmo desempenho com consumos menores de recursos, reduzindo, desta forma, a extração de materiais da natureza e a produção de resíduos e poluentes (JOHN, SJÖSTRÖM e AGOPYAN, 2002).

Neste contexto da busca pela redução do consumo de recursos naturais, associado ao aquecimento observado no setor da construção civil, verifica-se o incentivo às pesquisas que visem à busca de agregados alternativos, como aqueles resultantes de resíduos de processos industriais, comumente descartados na natureza. No Brasil, algumas pesquisas têm sido desenvolvidas na busca pela avaliação do uso da cinza do bagaço de canade-açúcar (CBC) em substituição parcial ao agregado miúdo para a confecção de pastas, argamassas e concretos ou, até mesmo, em substituição parcial do cimento Portland, uma vez que, conforme destacam Altoé et al. (2012), em caso de haver controle da temperatura de queima do bagaço da cana-de-açúcar, variando de $600^{\circ} \mathrm{C}$ a $650^{\circ} \mathrm{C}$, a cinza resultante apresenta características pozolânicas (Ganesan, Rajagopal e Thangavel (2007); Macedo (2009); Freitas (2005); Mensaneira (2010); Souto (2010); Alcantara e Santos (2011); Bessa (2011); Molin Filho (2012); Cordeiro, et al. (2012); Jiménez-Quero, et al. (2013).

\section{REVISÃO BIBLIOGRÁFICA}

\subsection{IMPACTOS AMBIENTAIS DA EXTRAÇÃO DE AREIA}

A extração de materiais aluvionares em rios (areias) vem sendo reprovada por diversos setores da sociedade em função dos desequilíbrios ambientais e sociais resultantes das atividades envolvidas no processo, além da preocupação com a escassez destes recursos devido à sua constante e crescente extração (OLIVEIRA e MELLO, 2007; MELO e CARVALHO, 2009).

Melo e Carvalho (2009) e Oliveira e Mello (2007) destacaram que, além de aspectos relacionados à escassez do produto, outros impactos negativos são resultantes do processo da extração de areia de leitos de rios durante as etapas de implantação (abertura de vias de acesso, remoção da vegetação às margens dos leitos e instalação de equipamentos), de operação (dragagem/retirada da areia submersa, estocagem da areia, drenagem, peneiramento, carregamento e transporte) e de desativação (retirada de equipamentos e recuperação das áreas afetadas), quais sejam: erosão e assoreamento, alteração da qualidade das águas superficiais e do nível do lençol freático, alteração da qualidade do ar, do solo e sonora, perda de espécies terrestres e aquáticas, proliferação de vetores, dentre outras.

Nesse aspecto, reforça-se a necessidade da elaboração de pesquisas que visem a substituição, mesmo que parcial, do uso de areia por agregados alternativos, principalmente direcionada à indústria da construção civil, na produção de argamassas e concretos, o que contribuirá com a diminuição da extração deste recurso da natureza.

\subsection{AGREGADOS ALTERNATIVOS PARA CONCRETOS E ARGAMASSAS}

Várias pesquisas têm sido realizadas abordando a temática da viabilidade técnica da substituição de agregado miúdo natural em concretos e argamassas por resíduos de diversas origens, tais como resíduos de plástico, resíduos cerâmicos, cinza da casca de arroz, cinza do bagaço da cana-de-açúcar, dentre outros (Cordeiro (2006); Marzouk, Dheilly e Queneudec (2007); Limbachiya (2009); Nunes (2009); Macedo (2009); 
Sales e Lima (2010); Souto (2010); Bessa (2011); Molin Filho (2012); Cordeiro et al. (2012).

Assim, considerando os fatores que influenciam diretamente a composição dos custos dos materiais de construção (transporte, combustível e produção), responsáveis por elevar substancialmente o valor unitário da construção, o emprego de materiais alternativos potencialmente viáveis economicamente, produzidos por meio de resíduos disponíveis em grande quantidade e diversidade, mostra-se como um campo vasto para pesquisas de aproveitamento e reciclagem na construção civil (Cincotto, Agopyan, John, 1988).

Neste contexto, a utilização de subprodutos e resíduos no desenvolvimento de materiais alternativos regionais com um baixo consumo de energia na produção e no transporte pode reduzir impactos gerados ao ambiente em função de extração de materiais naturais e deposição de resíduos oriundos de atividades industriais (Cincotto, Agopyan, John, 1988).

\subsection{A CINZA DO BAGAÇO DA CANA-DE-AÇÚCAR}

O Brasil é o maior produtor de cana-deaçúcar no mundo e também o principal exportador de seus derivados (etanol e açúcar). A Política Nacional de Biocombustíveis assegura ao setor a expectativa de grande desenvolvimento, por meio do incentivo à participação dos biocombustíveis na matriz de combustíveis brasileira, por serem resultantes de fontes renováveis e, também, por trazerem contribuições econômicas, sociais e ambientais (Bessa, 2012).

Assim como o vinhoto, torta de filtração, palha, levedura, dentre outros, o bagaço da canade-açúcar é um subproduto das agroindústrias sucroalcooleiras. Estima-se que toda energia necessária para o funcionamento do processo da usina (mecânico, elétrico, acionamento das bombas, moendas e para o processo de destilação e concentração do caldo) pode ser abastecido pelo sistema de cogeração de energia usando somente o bagaço de cana queimado nas caldeiras como fonte energética, o que pode tornar a usina energeticamente autossuficiente (Cordeiro, 2006; Freitas, 2005; Nunes et al., 2008; Nunes, 2009). Ainda, Freitas (2005) destaca que, mesmo que o processo de cogeração de energia libere dióxido de carbono $\left(\mathrm{CO}_{2}\right)$ para a atmosfera, a quantidade de emissões é significativamente menor se comparada com outras fontes de energia como o petróleo em função da produção da mesma quantidade de energia, o que acaba por corroborar estudos relacionados à produção de energia com processos alternativos e também estudos que abordem sobre possíveis aplicações técnicas com valor agregado para os resíduos oriundos de tais atividades.

\subsection{GERAÇÃO DA CINZA DO BAGAÇO DA CANA- DE-AÇÚCAR}

A geração da cinza do bagaço de cana-deaçúcar ( $C B C$ ) ocorre na queima do bagaço nas caldeiras durante o processo de cogeração de energia, sendo essa uma fase complementar do aproveitamento do bagaço de cana-de-açúcar no processo de obtenção do açúcar e álcool (Freitas, 2005).

Na Figura 1, visualizam-se ilustrações de algumas fases do processo de geração da CBC, desde o bagaço da cana-de-açúcar até o aspecto final da CBC de uma Usina sucroalcooleira situada na região de Maringá (PR), na qual a queima é realizada sem controle de temperatura.

Após o processo de queima do bagaço da cana-de-açúcar, o principal destino para a CBC são os depósitos junto ao local de saída, de onde serão removidas por caminhões tendo como destino a disposição em lavouras. No entanto, conforme destacam Paula (2006) e Altoé (2013), esta aplicação é inadequada e não atribui valor agregado à cinza do bagaço da cana-de-açúcar, uma vez que a CBC não possui características fertilizantes. 


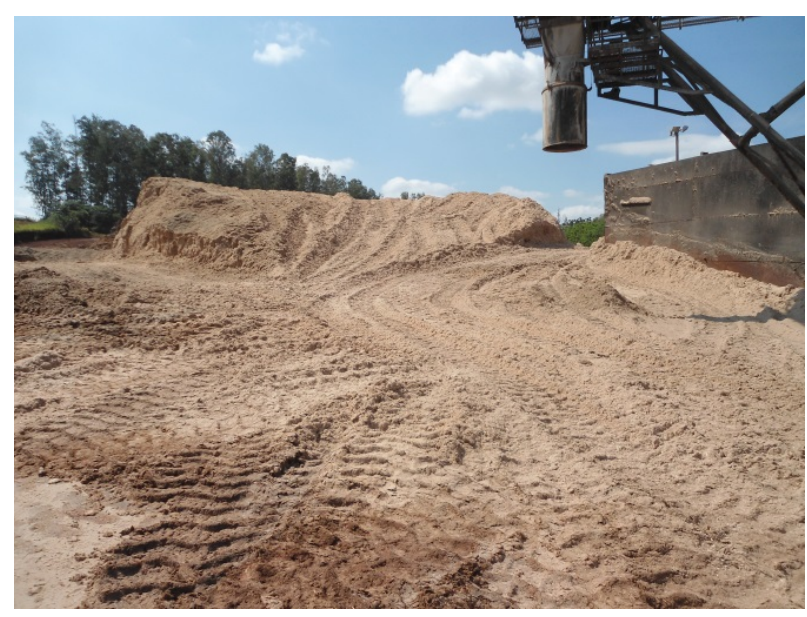

(a)

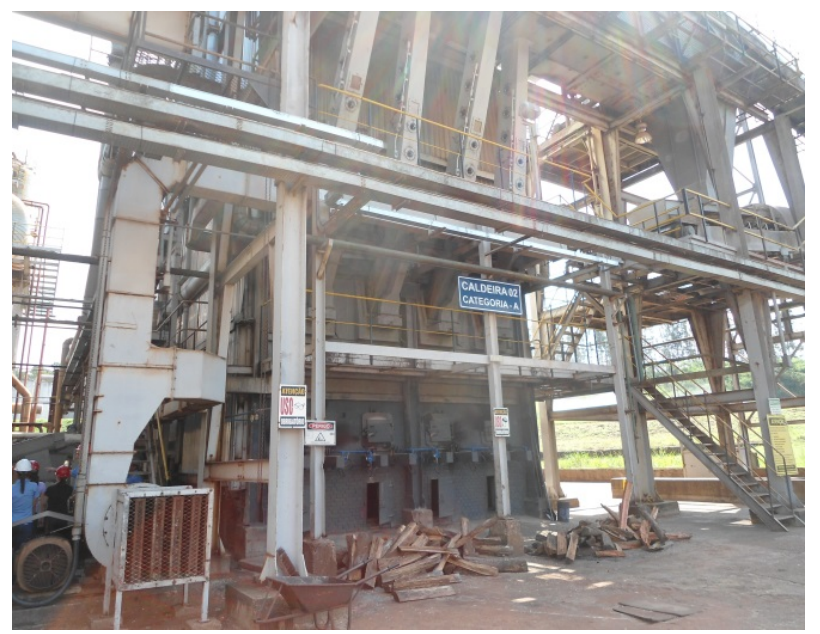

(c)

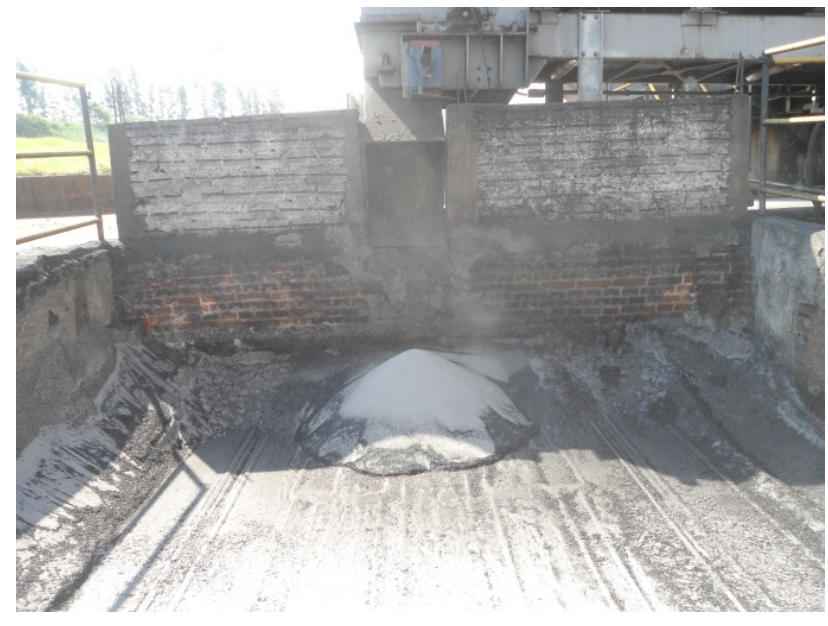

(e)

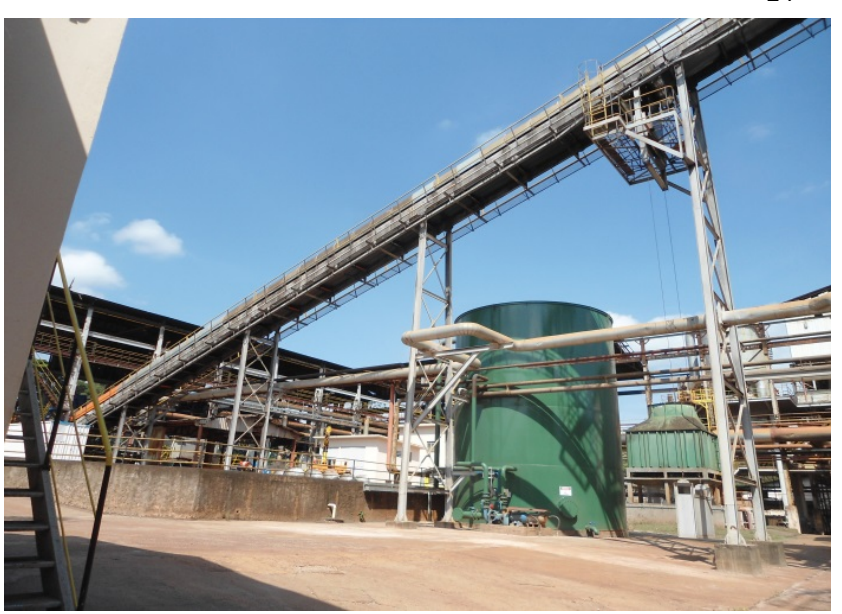

(b)

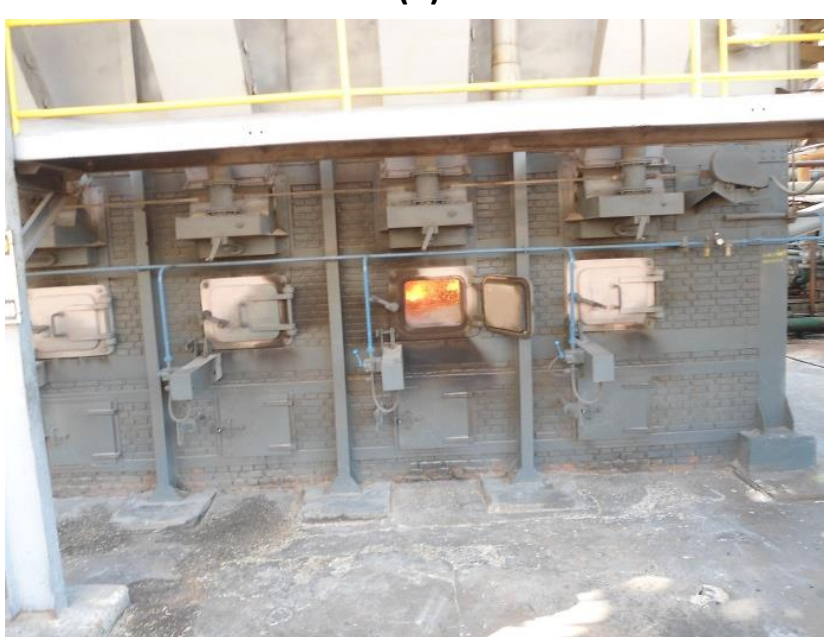

(d)

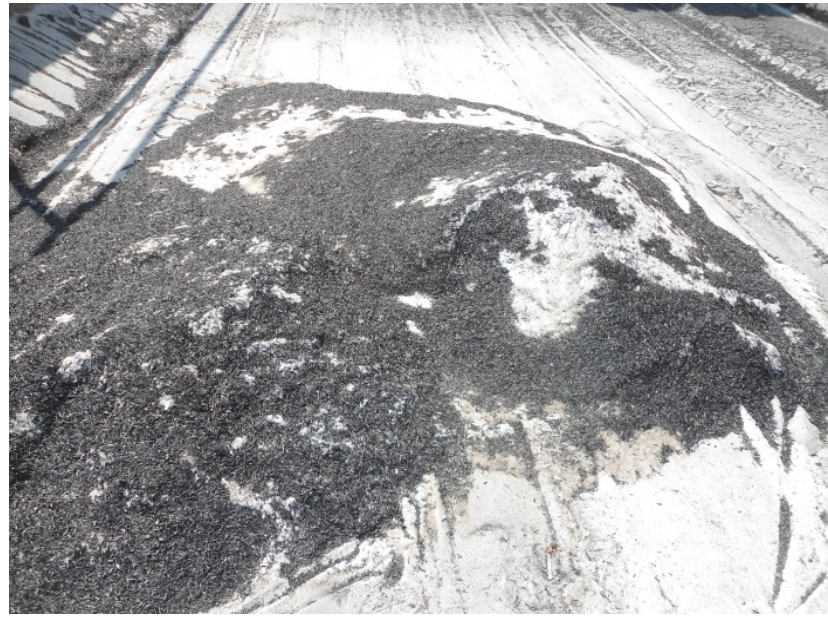

(f)

FIGURA 1: Ilustrações gerais do processo de geração e da própria CBC

(a) Depósito aberto do bagaço da cana-de-açúcar, (b) Entrada do bagaço nas caldeiras,

(c) Caldeiras para o processo de geração de energia (d) Fornos para queima do bagaço,

e) Saída da CBC no final do processo, (f) Aspecto final da CBC acumulada.

Após o processo de queima do bagaço da cana-de-açúcar, o principal destino para a CBC são os depósitos junto ao local de saída, de onde serão removidas por caminhões tendo como destino a disposição em lavouras. No entanto, conforme destacam Paula (2006) e Altoé (2013), esta aplicação 
é inadequada e não atribui valor agregado à cinza do bagaço da cana-de-açúcar, uma vez que a CBC não possui características fertilizantes.

\section{OBJETIVO E JUSTIFICATIVA}

Identificar o estado da arte sobre o estudo da utilização da cinza do bagaço da cana-de-açúcar como agregados para concretos e argamassas no intuito de coletar informações que possam subsidiar novas pesquisas relacionadas a essa temática.

O estudo do aproveitamento da cinza do bagaço da cana-de-açúcar em concretos e argamassas se justifica em função de ser uma opção no desenvolvimento da tecnologia de agregados alternativos para a indústria do concreto, valorizando a utilização de um subproduto agroindustrial gerado nas usinas sucroalcooleiras, agregando valor a um subproduto que é descartado em lavouras.

\section{METODOLOGIA}

Para a elaboração do presente estudo, procedeu-se ao levantamento bibliográfico e à compilação de resultados de pesquisas científicas constantes em periódicos nacionais e internacionais e em bancos de dissertações e teses acerca do emprego de cinza do bagaço da cana-de-açúcar como agregado miúdo em concretos e argamassas.

\section{PESQUISAS REALIZADAS COM O USO DE}

\section{CBC}

\subsection{CARACTERÍSTICAS DA CINZA DO BAGAÇO DA CANA-DE-AÇÚCAR}

Diversos são os fatores que influenciam as características da cinza do bagaço da cana-deaçúcar, dentre os quais se tem a temperatura de queima do bagaço, em que as variações da temperatura e do processo de queima alteram as tonalidades e propriedades da cinza (CORDEIRO, 2006).

A granulometria da cinza influencia no resultado de resistência mecânica dos compostos com adição de $C B C$, uma vez que os processos de moagem aumentam a superfície de contato das partículas da cinza, promovendo melhor reatividade, ganhos no arranjo físico entre os agregados e melhor empacotamento do composto (FREITAS, 2005).

A cinza poderá apresentar atividade pozolânica se as temperaturas e condições de queima do bagaço forem controladas, dessa forma, essa manterá suas propriedades amorfas, possibilitando o seu uso em concretos e argamassas, com finalidades cimentícias (CORDEIRO, TOLEDO FILHO, FAIRBAIRN, 2009).

$O$ elemento predominante nas cinzas é o dióxido de silício $\left(\mathrm{SiO}_{2}\right)$. A sílica e/ou silicato de alumínio podem estar no estado amorfo, que é uma condição favorável à reações pozolânicas, pois neste estado tais substâncias podem reagir com o hidróxido de cálcio e formar silicatos de cálcio hidratados, compostos diretamente relacionados com a resistência mecânica dos concretos, argamassas e pastas.

A grande quantidade de dióxido de silício, normalmente acima de $60 \%$ (em massa), presente na composição da cinza, tem origem no silício absorvido do solo pelas raízes na forma de ácido monossílico ( $\mathrm{H} 4 \mathrm{SiO} 4)$ e por meio da transpiração ocorre a saída da água das plantas, havendo, dessa forma, o deposito da substância na parede externa das células da epiderme como sílica gel. O silício acumulado forma uma barreira física entre cutícula e a parede das células da epiderme impedindo à penetração de fungos patogênicos e reduzindo as perdas de água por transpiração (BARBOZA FILHO, PRABHU, 2002).

De acordo com Cordeiro (2006), outra possível fonte de sílica presente na cinza é a areia (quartzo), proveniente da lavoura e que durante o processo de lavagem da cana-de-açúcar não é totalmente removida, permanecendo no bagaço, podendo ser observado esse excesso nas operações de limpeza das caldeiras onde ocorre a combustão.

As Tabelas 1 e 2 apresentam as características químicas e físicas de CBCs estudadas por alguns pesquisadores. 
TABELA 1: Caracterização química da CBC apresentadas em alguns trabalhos

Elemento

CORDEIRO (2006) DE PAULA et al. (2009) BORLINI et al. (2006)

BESSA (2011)

\begin{tabular}{|c|c|c|c|c|}
\hline $\mathrm{SiO}_{2}$ & 78,34 & 83,71 & 77,50 & 93,50 \\
\hline $\mathrm{Al}_{2} \mathrm{O}_{3}$ & 8,55 & & 4,70 & \multirow{2}{*}{3,80} \\
\hline $\mathrm{Fe}_{2} \mathrm{O}_{3}$ & 3,61 & 6,54 & 3,80 & \\
\hline $\mathrm{TiO}_{2}$ & 0,50 & 1,16 & 0,30 & 0,50 \\
\hline $\mathrm{CaO}$ & 2,15 & 1,18 & 2,30 & 0,40 \\
\hline MgO & 1,65 & - & 3,00 & 0,30 \\
\hline $\mathrm{SO}_{3}$ & - & 0,68 & - & $<0,10$ \\
\hline $\mathrm{K}_{2} \mathrm{O}$ & 3,46 & 6,15 & 5,40 & \multirow{2}{*}{0,80} \\
\hline $\mathrm{Na}_{2} \mathrm{O}$ & 0,12 & - & - & \\
\hline $\mathrm{P}_{2} \mathrm{O}_{5}$ & 1,07 & - & 2,30 & 0,20 \\
\hline MnO & 0,13 & 0,08 & 0,30 & - \\
\hline $\mathrm{BaO}$ & $<0,16$ & - & - & - \\
\hline $\mathrm{ZrO}_{2}$ & - & 0,30 & 0,06 & - \\
\hline $\mathrm{Cr}_{2} \mathrm{O}_{3}$ & - & 0,09 & - & - \\
\hline $\mathrm{Sc}_{2} \mathrm{O}_{3}$ & - & 0,04 & - & - \\
\hline $\mathrm{ZnO}$ & - & 0,04 & - & - \\
\hline $\mathrm{V}_{2} \mathrm{O}_{5}$ & - & 0,03 & - & - \\
\hline $\mathrm{Fe}_{2} \mathrm{O}$ & - & - & - & - \\
\hline rda ao fogo & 0,42 & - & 0,31 & 0,35 \\
\hline
\end{tabular}

TABELA 2: Características físicas da CBC apresentadas em alguns trabalhos

\begin{tabular}{ccccc} 
& NUNES (2009) & $\begin{array}{c}\text { DE PAULA et al. } \\
(\mathbf{2 0 0 9 )}\end{array}$ & CORDEIRO (2006) & BESSA (2011) \\
\hline Massa Específica $\left(\mathrm{g} / \mathrm{cm}^{3}\right)$ & 2,60 & & 2,53 & 2,23 a 2,63 \\
\hline Diâmetro Máximo $(\mathrm{mm})$ & 0,20 & 0,014 & 0,045 & 0,60 a 1,20 \\
\hline Módulo de Finura & - & - & - & 0,52 a 1,46 \\
\hline
\end{tabular}




\subsection{CLASSIFICAÇÃO DA CBC SEGUNDO A ABNT NBR 10004:2004}

Segundo Nunes (2009) sobre as características físicas e químicas da cinza do bagaço de cana-de-açúcar ( $C B C$ ) para uso na construção, foram analisadas $\mathrm{CBC}$ geradas por quatro usinas localizadas na região metropolitana de Maringá $(P R)$, nas quais o processo de queima é realizado sem controle de temperatura.

Resultados obtidos por Cordeiro (2006) e Nunes (2009) demonstraram uma fase altamente cristalina na forma de quartzo (normalmente acima de $\mathrm{SiO}_{2}$ em massa), baixo índice de atividade pozolânica, massa específica próxima do valor da areia natural utilizada no trabalho, apresentando-se como um material inerte e sem risco ambiental. Pelas características apresentadas, a CBC é classificada como um resíduo sólido de categoria rural e natureza de classe II (não inertes) segundo a ABNT NBR 10004:2004.

Desta forma, os resultados apresentados demonstraram ser possível a elaboração de estudos que visem a utilização desta $C B C$ em concretos e argamassas como material fino em sua composição, uma vez que esta caracteriza-se como material inerte.

\subsection{USO DE CBC NO DESENVOLVIMENTO DE CONCRETOS ESPECIAIS}

A utilização tecnicamente controlada de resíduos industriais para a produção de novos materiais contribui significativamente para a preservação da extração dos recursos do meio ambiente. Essa iniciativa possibilita uma destinação técnica e de valor agregado aos resíduos. Nessa direção, as tecnologias especiais de concreto que representam alguns dos principais avanços nos desenvolvimentos de materiais de construção civil, devem oportunizar na sua concepção a utilização de agregados e aglomerantes alternativos, tais como aqueles oriundos de estudos de reaproveitamento, como, por exemplo, a cinza do bagaço da cana-de-açúcar.

Nos estudos de Cordeiro (2006) verificouse entre outros aspectos, o uso da CBC ultrafina com controle do tempo de queima e moagem para produção de concretos convencionais e de alto desempenho. As informações obtidas demonstraram que nas condições controladas da CBC ultrafina é possível produzir concretos de alto desempenho tecnológico com redução significativa do impacto ambiental. $\mathrm{O}$ autor enfatiza que com a utilização da CBC é possível manter as propriedades mecânicas de durabilidade com preservação das propriedades reológicas.

Outro exemplo de aplicação para a CBC em concretos especiais foi desenvolvido no trabalho de Leal e Castro (2007). Os autores concluíram que perante a análise matemática e estatística realizadas nos experimentos com concreto, que a $C B C$ pode ser usada como material fino em misturas para concretos asfálticos betuminosos.

Poggiali (2010) objetivou avaliar o desempenho de microconcretos fabricados com clínquer, gesso e diferentes adições de cinzas de bagaço de cana. Os resultados com relação ao índice de atividade pozolânica e de condutividade indicaram que a moagem é um fator que influencia diretamente na reatividade das cinzas. Foi relacionado pela autora que, as cinzas finas e grossas, embora possuíssem diferentes dosagens de $\mathrm{SiO} 2$, proporcionaram ao microconcreto ganhos de desempenho da ordem de 10 a $12 \%$.

Rukzon e Chindaprasirt (2012) procuraram avaliar o uso da CBC em substituição parcial do cimento portland para produção de concretos de alta resistência. De uma maneira geral, os autores recomendam que a substituição de até $30 \%$ é viável para a produção de concreto de alta resistência na faixa de $65 \mathrm{MPa}$ de resistência à compressão aos 28 dias. Até esta faixa de incorporação de CBC é possível diminuir as penetrações de cloreto com consequente melhoria de resistência.

O objetivo do desenvolvimento de concretos com alto desempenho em durabilidade sempre figurou como uma das principais intenções de pesquisas sobre concreto. Foi justamente isso que fizeram os pesquisadores mexicanos Maldonado-Bandala et al. (2011). Nesse trabalho, foi evidenciado que a presença da CBC em substituição parcial ao cimento Portland contribui 
para a redução da corrosão induzida por íons de cloreto e sulfato. Desta forma, foram evidenciadas melhorias na durabilidade do concreto durante quatorze meses da avaliação, a qual foi realizada por meio de investigações electroquímicas de potencial de corrosão. Nesta mesma perspectiva pela busca de concretos com alto desempenho em durabilidade, os pesquisadores Núñes-Jaquez et al. (2012) realizaram as suas investigações. Também foi enfatizado que o concreto que continha $C B C$, neste caso $20 \%$ em substituição da massa de cimento, apresentou as menores taxas de corrosão, contribuindo significativamente para o desempenho da durabilidade.

Nos desenvolvimentos de Alcantara e Santos (2011) foi utilizada a CBC cristalina para o desenvolvimento de concreto autoadensável. Foi constatado que a CBC atuou de forma satisfatória na formação da pasta e no controle da segregação. A finura muito elevada da cinza e a sua alta superfície específica requerem controles técnicos no processo de dosagem. Segundo os autores, a CBC atua diretamente no controle da segregação.

De acordo com Alcantara e Santos (2012), a composição fina da CBC é responsável direta para a viabilização do concreto autoadensável fresco e suas dosagens têm ligação direta com os aspectos de resistência do material. Também estão associadas à $C B C$ contribuições diretas ao ajuste do esqueleto granular. Eles ainda informaram que as cinzas possuem relação direta com a ductilidade, proporcionando maior rigidez com o passar do tempo ao concreto autoadensável.

Nas investigações de Molin Filho (2012), também foi desenvolvida uma composição de concreto autoadensável, sendo essa composta pelo seguinte traço unitário: $1: 1,8: 0,2: 2.21: 0,45: 0,40$ : 0,0055 (cimento: areia: CBC: brita: água: filer: superplastificante). Nesse desenvolvimento, comprovou-se que a substituição de $10 \%$ em massa de areia por CBC foi viável para a produção de concreto autoadensável (CAA). Para realização das comparações técnicas, também foi desenvolvido um traço de CAA sem a CBC. Evidenciou-se que a CBC utilizada nesta pesquisa em substituição direta pela areia, na taxa de $10 \%$, requer dosagens de materiais muito próximas, para a manutenção das propriedades autoadensáveis do CAA. O consumo de cimento por metro cúbico de concreto para ambos os traços esteve em patamares de 400 $\mathrm{kg} / \mathrm{m}^{3}$. Este fato também foi evidenciado na dosagem de superplastificante por cimento, que foi de $0,55 \%$ para os dois traços. Dentro dos critérios técnicos estabelecidos, o autor concluiu que é possível utilizar a $C B C$ na produção de $C A A$, sem que haja prejuízo nas propriedades reológicas e mecânicas, mantendo inclusive, os mesmos índices de consumo de superplastificante e cimento. Relevou-se, também, que com a substituição parcial da areia por $C B C$ é possível reduzir o consumo de areia de $89,2 \mathrm{~kg} / \mathrm{m}^{3}$ no CAA.

\subsection{COMPILAÇÃO DE ALGUNS DADOS DE PESQUISAS SOBRE O USO DE CBC}

São crescentes as universidades e centros que vêm desenvolvendo pesquisas visando 0 emprego da CBC como agregado em produtos para construção civil. Algumas destas aplicações são destacadas no Quadro 1.

QUADRO 1: Resultados compilados do uso de CBC em Concretos e Argamassas.

\begin{tabular}{|c|c|c|c|}
\hline Pesquisa & $\begin{array}{c}\text { Tipo de } \\
\text { Concreto/ } \\
\text { Argamassa }\end{array}$ & $\begin{array}{c}\text { Substituição } \\
\text { da areia por } \\
\text { CBC (\%) }\end{array}$ & Aspectos constatados \\
\hline $\begin{array}{c}\text { Modania e } \\
\text { Vyawahareb } \\
(2013)\end{array}$ & $\begin{array}{c}\text { Concreto } \\
\text { Convencional }\end{array}$ & $10-20 \%$ & $\begin{array}{l}\text { Com a fração de substituição proposta, verificou-se que não há } \\
\text { perda de trabalhabilidade ou de resistência do concreto. Ainda, } \\
\text { os resultados de resistência à compressão indicam que pode } \\
\text { haver propriedades pozolânicas na cinza do bagaço da cana-de- } \\
\text { açúcar. }\end{array}$ \\
\hline
\end{tabular}


QUADRO 1: Resultados compilados do uso de CBC em Concretos e Argamassas (CONTINUAÇÃO).

\begin{tabular}{|c|c|c|c|}
\hline $\begin{array}{c}\text { Molin Filho } \\
\text { (2012) }\end{array}$ & $\begin{array}{c}\text { Concreto } \\
\text { Autoadensável } \\
\text { (CAA) }\end{array}$ & $10 \%$ & $\begin{array}{l}\text { A utilização da CBC no CAA não alterou as propriedades } \\
\text { reológicas nos aspectos de fluidez, coesão e consistência. } \\
\text { Ainda, não se observou diferenças consideráveis nos valores } \\
\text { obtidos nas resistências à compressão axial e à tração, em } \\
\text { relação ao CAA sem CBC. Não foram realizados ensaios de } \\
\text { durabilidade do material. }\end{array}$ \\
\hline $\begin{array}{c}\text { Alcantara e } \\
\text { Santos } \\
\text { (2011) }\end{array}$ & $\begin{array}{c}\text { Concreto } \\
\text { Autoadensável } \\
\text { (CAA) }\end{array}$ & $\begin{array}{c}\text { Não } \\
\text { especificado }\end{array}$ & $\begin{array}{l}\text { Em decorrência da finura e da superfície específicas muito } \\
\text { elevadas, as composições com } C B C \text { requerem alto teor de água } \\
\text { em sua composição, influenciando nos valores de resistência } \\
\text { mecânica. Constatou-se também que a CBC atua diretamente } \\
\text { no efeito da segregação, trazendo contribuição de melhoria, } \\
\text { sendo, desta maneira, viável o uso da CBC como fino em CAA. }\end{array}$ \\
\hline Bessa (2011) & $\begin{array}{l}\text { Concreto para } \\
\text { artefatos de } \\
\text { infraestrutura }\end{array}$ & $30 \%$ & $\begin{array}{l}\text { Não interferiu na durabilidade dos concretos analisados. Nas } \\
\text { análises de lixiviação e solubilização, verificou-se que a CBC não } \\
\text { afetou a alcalinidade da matriz cimentícia e, ainda, que a } \\
\text { mesma não oferece riscos ao meio ambiente, podendo ser } \\
\text { utilizada como substituto parcial do agregado miúdo. }\end{array}$ \\
\hline Souto (2010) & $\begin{array}{c}\text { Concreto } \\
\text { Convencional } \\
\text { (CCV) }\end{array}$ & $15 \%$ & $\begin{array}{l}\text { O emprego de CBC promoveu aumento nos resultados de } \\
\text { resistência à compressão axial do CCV, chegando a } 11,81 \% \\
\text { superior em comparação ao concreto sem utilização da CBC, } \\
\text { efeito esse atribuído ao preenchimento dos poros da matriz } \\
\text { cimentícia pelo grão de CBC. Apresentou relação a/c elevado } \\
\text { para maiores substituições. }\end{array}$ \\
\hline $\begin{array}{l}\text { Sales e Lima } \\
\quad(2010)\end{array}$ & $\begin{array}{c}\text { Argamassa } \\
\text { Convencional e } \\
\text { Concreto } \\
\text { Convencional }\end{array}$ & $20-30 \%$ & $\begin{array}{l}\text { As argamassas produzidas com substituição parcial da areia por } \\
\text { CBC mostraram resultados mecânicos mais satisfatórios que as } \\
\text { amostras de referência. Concluiu-se que a } C B C \text { pode ser } \\
\text { utilizado como um substituto parcial de areia em concretos e } \\
\text { argamassas. }\end{array}$ \\
\hline $\begin{array}{c}\text { Macedo } \\
(2009)\end{array}$ & $\begin{array}{c}\text { Argamassa } \\
\text { convencional } \\
\text { (cimento, areia e } \\
\text { CBC) }\end{array}$ & $10 \%$ & $\begin{array}{l}\text { Em todos os teores de substituição propiciou a redução da } \\
\text { absorção por capilaridade, propriedade atribuída ao } \\
\text { preenchimento dos vazios, dificultando o ingresso de agentes } \\
\text { agressivos à argamassa. }\end{array}$ \\
\hline $\begin{array}{l}\text { Baguant } \\
(1995)\end{array}$ & $\begin{array}{c}\text { Concreto } \\
\text { Convencional }\end{array}$ & $75 \%$ & $\begin{array}{l}\text { A substituição observada resultou em resistências à } \\
\text { compressão similares tanto para o concreto com areia natural } \\
\text { quanto para aquele com } 75 \% \text { de substituição por } C B C \text {, além de } \\
\text { similaridade nos dados referentes aos parâmetros de } \\
\text { durabilidade de ambos os concretos, quais sejam: resistência à } \\
\text { abrasão mecânica, absorção de água, difusão de cloretos e } \\
\text { carbonatação. O concreto com CBC apresentou também maior } \\
\text { resistência ao congelamento-descongelamento. }\end{array}$ \\
\hline
\end{tabular}

\section{CONCLUSÃO}

A partir dos dados destacados, é possível concluir que há viabilidade técnica na utilização da CBC como agregado miúdo nos concretos convencionais, autoadensáveis e argamassas dos estudos experimentais apresentados. Com isso, tem-se um ganho ambiental considerável, uma vez que se dá um destino técnico com valor agregado ao resíduo da queima do bagaço da cana-de-açúcar e, por conseguinte, diminui-se a extração de areia de leitos dos rios, evitando uma série de impactos negativos oriundos da atividade de extração.

Deste modo, verifica-se que os estudos com a utilização da CBC como agregado sinalizam o desenvolvimento de tecnologias que trazem melhorias ao setor de concretos para uma aplicação de forma racional e sustentável na indústria da construção civil. No entanto, estudos a respeito da durabilidade de concretos e argamassas com CBC em sua composição devem ainda ser mais explorados, no intuito de que, futuramente, esse resíduo possa ser caracterizado como subproduto 
e, portanto, utilizado na produção de concretos e argamassas.

Vale destacar que os estudos que permearam o presente trabalho fizeram uso de CBC advindos de localidades diferentes, o que resultou em diferenças consideráveis nas características das amostras estudadas, uma vez que o processo de moagem, de queima do bagaço, dentre outros processos, interferem nestas características. Ainda, conforme observado nos estudos, houve variação entre os percentuais de substituição da areia natural por CBC em concretos e argamassas. Por estas razões, enfatiza-se que estudos específicos devem ser realizados para cada caso em que se deseja fazer a aplicação de determinada $\mathrm{CBC}$, principalmente em função das características do material. Portanto, os valores compilados no presente trabalho representam apenas parâmetros de referência para pesquisas futuras.

\section{REFERÊNCIAS BIBLIOGRÁFICAS}

ALCANTARA, M. A. M.; SANTOS, B. V. D. O uso de cinzas de bagaço de cana como finos do concreto autoadensável. In: $53^{\circ}$ Congresso Brasileiro do Concreto IBRACON. Anais... Florianópolis, 2011.

ALTOÉ, S.P.S. Estudo da potencialidade da utilização da mistura de cinza do bagaço de cana-de-açúcar e resíduos de pneus na confecção de concretos e pavers para pavimentação. 2013. Dissertação (Mestrado em Engenharia Urbana) - Universidade Estadual de Maringá, Maringá, 2013.

ALTOÉ, S.P.S. et al. Análise da Pozolanicidade da cinza do bagaço de cana-de-açúcar em diferentes temperaturas de queima. In: SIMPGEU 2012 - Simpósio de Pós Graduação em Engenharia Urbana, 2012, Maringá. Anais... Simpósio de Pós-Graduação em Engenharia Urbana, 2012.

ASSOCIAÇÃO BRASILEIRA DE NORMAS TÉCNICAS, ABNT NBR 15823-1. Concreto auto-adensável. Parte 1: Classificação, controle e aceitação no estado fresco. Rio de Janeiro, 2010.

ABNT NBR 10004. Resíduos Sólidos - Classificação. Rio de Janeiro, 2004

BAGUANT, K. Properties of concrete with bagasse ash as fine aggregate. In: International Conference on Fly Ash, Silica Fume, Slag and Natural Pozzolans in Concrete CANMET/ACI, 5, 1995, Milwaukee. Proceedings... Detroit: American Concrete Institute, 1995. v. 1, p. 315-337.
BESSA, S. A. L. Utilização Da Cinza Do Bagaço Da CanaDe-Açúcar Como Agregado Miúdo Em Concretos Para Artefatos De Infraestrutura Urbana. 2011. Tese (Doutorado em Engenharia Urbana) - Universidade Federal de São Carlos, São Carlos, 2011.

BORLINI, M. C.; MENDONÇA, J. L. C. C.; VIEIRA, C. M. F.; MONTEIRO, S.N. Influência da Temperatura de Sinterização nas Propriedades Físicas, Mecânicas e Microestruturais de Cerâmica Vermelha Incorporada com Cinza de Bagaço de Cana-de-açúcar. Rio de Janeiro: UFRJ, 2006. Disponível em: http://www.materia.coppe.ufrj.br/sarra/artigos/artigo1 0799/. Acesso em: 26 nov. 2011.

CINCOTTO, M. A., AGOPYAN, V., JOHN, V. M. Optimization of rice husk ash production. In: International Symposium on Vegetable Plants and Their Fibers as Building Materials. Preceedings... Salvador, Brazil, v. 2, p. 334-342, 1988.

CORDEIRO, G. C. Utilização de cinzas ultrafinas do bagaço de cana-de-açúcar e da casca de arroz como aditivos minerais em concreto. 2006. 445f. Tese (Doutorado em Ciências em Engenharia Civil) Universidade Federal do Rio de Janeiro, Rio de Janeiro, 2006.

CORDEIRO, G. C.; TOLEDO FILHO, R. D.; FAIRBAIRN, E. M. Caracterização de Cinza do Bagaço de Cana-deaçúcar para Emprego como Pozolana em Materiais Cimentícios. Revista Química Nova, 32, 1, p 82-86, 2009.

CORDEIRO, G. C. et al. Experimental characterization of binary and ternary blended-cement concretes containing ultrafine residual rice husk and sugar cane bagasse ashes. Construction \& Building Materials, v. 29, p. 641-646, 2012.

DE PAULA, M. O. D. ; RODRIGUES, C. D. S.; SILVA, E. N. D.; SOUZA, C. D. F. Avaliação Da Atividade Pozolânica Da Cinza Do Bagaço De Cana-De-Açúcar. Revista Engenharia na agricultura, v. 17, p 15-20, 2009.

FREITAS, E. S. Caracterização da cinza do bagaço da cana-de-açúcar do município de campos dos Goytacazes para uso na construção civil. 2005. Dissertação (Mestrado em Engenharia) - Universidade Estadual do Norte Fluminense Darcy Ribeiro, Rio de Janeiro, 2005.

JIMÉNEZ-QUERO, V.G. et al. Influence of sugar-cane bagasse ash and fly ash on the rheological behavior of cement pastes and mortars. Construction and Building Materials, Vol. 40, Mar/2013.

GANESAN, K.; RAJAGOPAL, K.; THANGAVEL, K. Evaluation of bagasse ash as supplementary cementitious material. Cement and Concrete Composities, Barking, v. 29, p.515-524, 2007. 
GOMES, P. C. C. Optimization and Characterization of High-Strength Self- Compacting Concrete. 2002, 139 p. Tese (Doutorado em Engenharia Civil), Universitat Politècnica de Catalunya, Barcelona, 2002.

JOHN, V.M.; SJÖSTRÖM, C.; AGOPYAN, V. Durability in the built environment and sustainability in developing countries. In: International Conference on Durability of Building Materials and Components, 9., 2002, Brisbane 9th DBMC. Proceedings... Melbourne: CSIRO, 2002.

LEAL, C. L. D.; CASTRO, P. F. Aproveitamento da cinza do bagaço da cana-de-açúcar como fíler em concreto asfáltico. Revista Vértices, v. 9, n. 1, 2007.

LIMBACHIYA, M.C. Bulk engineering and durability properties of washed glass sand concrete. Construction and Building Materials, 23 (2), p. 1078-1083, 2009.

MACEDO, P. C. Avaliação de argamassas com adição da cinza do bagaço de cana-de-açúcar. 2009. 116p. Dissertação (Mestrado em Engenharia Civil), Universidade Estadual Paulista, Ilha Solteira, 2009.

MALDONADO-BANDALA, E. E.; et al. 2011. Electrochemical Characterization of Modified Concretes with Sugar Cane Bagasse Ash. International Journal Eletrochemical Science, v. 6, p. 4915-4926, 2011.

MARTINS, C. H., ZANELLA, R. M., PAULINO JÚNIOR, R. Potencial do uso de cinza do bagaço e cana-de-açúcar como agregado miúdo. In: I Seminário de engenharia urbana da universidade estadual de Maringá. Anais... Maringá, Universidade Estadual de Maringá, 2007. p. 121-126.

MARZOUK, O.Y.; DHEILLY, R.M.; QUENEUDEC, M. Valorization of post-consumer waste plastic in cementitious concrete composites. Waste Management, 27, pp. 310-318, 2007.

MELO, T. F. S.; CARVALHO, S. M. Avaliação dos impactos ambientais causados pela extração mineral: o caso do Porto de Areia Estrela. In: 12을 Encontro de Geógrafos da América Latina, 2009, Montevideo. Anais... Montevideo: Easy Planners, v. 1, p. 1-12, 2009.

MENSANEIRA, E.C. Verificação da potencialidade do uso da cinza do bagaço da cana de açúcar em substituição parcial ao cimento Portland. 2010. 116f. Dissertação (Mestrado em Engenharia de Edificações e Saneamento) - Universidade Estadual de Londrina, Londrina, 2010.

MODANIA, P. O.; VYAWAHAREB, M. R. Utilization of Bagasse Ash as a Partial Replacement of Fine Aggregate in Concrete. Procedia Engineering, 51, 2013, p.25 - 29.

MOLIN FILHO, R G. D. Concreto autoadensável com a utilização da cinza do bagaço de cana. 2012. Dissertação (Mestrado em Engenharia Urbana) - Universidade Estadual de Maringá, Maringá, 2012.
NUNES, I. H. S. Estudo das características físicas e químicas da cinza do bagaço de cana-de-açucar para uso na construção. 2009, 65f. Dissertação (Mestrado em Engenharia Urbana) - Universidade Estadual de Maringá, Maringá, 2009.

NUNES, I. H. S. et al. Estudo das características físicas e químicas da cinza do bagaço de cana-de-açúcar para uso na construção. Revista Tecnológica (UEM), v. 17, p. 3948, 2008.

NÚÑES-JAQUEZ, R. E., et al. Corrosion of Modified Concrete with Sugar Cane Bagasse Ash. International Journal of Corrosion, v. 2012, 2012.

OLIVEIRA, F.L., MELLO, E.F. A mineração de areia e os impactos ambientais na bacia do rio São João, RJ. Revista Brasileira de Geociências, Rio de Janeiro, 37(2), p. 374389, jun./2007.

PAULA, M. O. Potencial da cinza do bagaço de cana-deaçúcar como material de substituição parcial de cimento Portland. 2006. 60f. Dissertação (Mestrado em Engenharia Agrícola) - Universidade Federal de Viçosa, Viçosa, 2006.

POGGIALI, F. S. J. Desempenho de microconcretos fabricados com cimento Portland com adições de cinza de bagaço de cana-de-açúcar. 2010. 149 f. Dissertação (Mestrado em Construção Civil) - Universidade Federal de Minas Gerais, Belo Horizonte, 2010.

RUKZON, S.; CHINDAPRASIRT, P. Utilization of bagasse ash in high-strength concrete. Materials and Design, v. 34, p. 45-50, 2012.

SALES, A.; LIMA, S.A. Use of Brazilian sugarcane bagasse ash in concrete as sand replacement. Waste Management, Vol. 30 (6), Jun/2010. p. 1114-1122.

SOUTO, J. M. F. Avaliação do desempenho da cinza do bagaço de cana-de-açúcar na produção de concretos. 2010. Dissertação (Mestrado em Engenharia Urbana) Universidade Estadual de Maringá, Maringá, 2010. 